\title{
Mutations in KRAS codon 12 predict poor survival in Chinese patients with metastatic colorectal cancer
}

\author{
BINGJUN BAI ${ }^{1,2}$, LINA SHAN ${ }^{1,2}$, BINBIN XIE $^{3}$, XUEFENG HUANG $^{1}$, \\ WEIFANG MAO ${ }^{1}$, XIAOWEI WANG ${ }^{1}$, DA WANG $^{1}$ and HONGBO ZHU $^{1,2}$ \\ ${ }^{1}$ Department of Colorectal Surgery, Sir Run Run Shaw Hospital, School of Medicine, Zhejiang University; \\ ${ }^{2}$ Key Laboratory of Biotherapy of Zhejiang; ${ }^{3}$ Department of Medical Oncology, Sir Run Run Shaw Hospital, \\ School of Medicine, Zhejiang University, Hangzhou, Zhejiang 310016, P.R. China
}

Received February 1, 2017; Accepted November 16, 2017

DOI: $10.3892 / \mathrm{ol} .2017 .7709$

\begin{abstract}
KRAS mutations serve a function in tumorigenesis of colorectal cancer (CRC) and guide the use of targeted drugs. However, the prognostic value of KRAS mutations and their subtypes remain controversial. The present study aimed to investigate the correlations between KRAS mutations and clinicopathological characteristics, and their prognostic significance in Chinese patients with metastatic CRC (mCRC). A total of 135 patients with $\mathrm{mCRC}$ were analyzed for KRAS mutations. Mutations in codon 12 and 13 were identified in $45(33.3 \%)$ patients. Only 3 patients harbored a mutation of V600E. Compared with male patients, KRAS codon 12 mutations were more common in female patients $(\mathrm{P}<0.05)$. KRAS codon 13 mutations tended to arise in right-sided compared with left-sided colon cancer $(\mathrm{P}<0.05)$. Survival analysis was performed in 101 patients receiving primary tumor resection. Compared with KRAS codon 12 wild-type, codon 12 mutations were markedly correlated with a poorer survival (log-rank $\mathrm{P}=0.002)$. No prognostic significance was revealed in codon 13 mutations. In univariate analysis, mortality risk was significantly increased by subtypes of G12D and G12V [hazard ratio $(\mathrm{HR})=2.313,95 \%$ confidence interval $(\mathrm{CI})=1.069-5.004$, $\mathrm{P}=0.03 ; \mathrm{HR}=2.621,95 \% \mathrm{CI}=1.057-6.497, \mathrm{P}=0.04$, respectively]. The results of the present study suggested that codon 12 mutations, in particular G12D and G12V, predicted a negative prognosis in Chinese patients with mCRC. These findings require further confirmation via prospective studies with larger samples.
\end{abstract}

Correspondence to: Dr Hongbo Zhu, Department of Colorectal Surgery, Sir Run Run Shaw Hospital, School of Medicine, Zhejiang University, 3 East Qingchun Road, Hangzhou, Zhejiang 310016, P.R. China

E-mail: drzhuhongbo@yahoo.com

Key words: colorectal cancer, KRAS mutations, KRAS codon 12, overall survival, prognosis

\section{Introduction}

Colorectal cancer (CRC) is one of the leading causes of cancer-associated mortalities in developed countries (1). In the past two decades, the morbidity and mortality of CRC have risen rapidly in Chinese population (2). A systemic therapy involving neoadjuvant therapy, surgical resection and postoperative therapy provides an opportunity for long-term survival. However, the majority of patients with metastatic CRC (mCRC) experience a poor survival rate $(3,4)$. A growing body of research has demonstrated the positive effect of molecularly targeted treatment on the survival rate of patients with mCRC, especially with the use of monoclonal antibodies against epidermal growth factor receptor (EGFR) $(5,6)$.

The tumorigenesis of CRC is a multistep process through the accumulation of genetic alterations. KRAS mutations are considered to be an early event in tumorigenesis (7). Proteins expressed by KRAS and BRAF genes are involved in the $\mathrm{Ras} / \mathrm{Raf} / \mathrm{mitogen}$-activated protein kinase-extracellular-signal-regulated kinase kinase (MEK)/extracellular-signal-regulated kinase signaling pathway, which is a downstream pathway of EGFR. Mutations in $K R A S$ and $B R A F$ genes lead to the persistent activation of this pathway and accelerate the proliferation of tumor cells (8). It has been widely accepted that KRAS mutations predict the poor efficacy of anti-EGFR therapy in patients with mCRC (9). However, whether KRAS mutations are correlated with decreased survival in patients with $\mathrm{mCRC}$ remains controversial. Previous studies have indicated that KRAS mutations present statistically significant reductions in overall survival (OS) and disease-free survival (DFS) (10-12). Nevertheless, evidence of the association between KRAS mutations and poor OS in patients with $\mathrm{mCRC}$ is obtained primarily in Western countries and certain Asian countries; few data about prognostic significance of KRAS mutations in $\mathrm{mCRC}$ are available in Chinese patients (10-12).

Approximately $90 \%$ of KRAS mutations are located in codon 12 and 13 (13). Certain studies have demonstrated the diversity of biological characteristics in CRC with distinct KRAS mutational sites $(14,15)$. An in vitro study revealed that tumor cells with codon 12 mutations possess an increased ability for cell transformation compared with those with codon 
13 mutations (16). However, in other studies, codon 13 mutations are considered to be more relevant to the poorer outcome than codon 12 mutations $(17,18)$. Compared with codon 12 mutations, codon 13 mutation (G13D) exhibits increased efficacy of cetuximab treatment (15).

The results from previous studies did not reach a consensus and very few studies were performed to analyze KRAS mutation subtypes in Chinese patients with $\mathrm{mCRC}$. Thus, the present study aimed to identify the frequency of $K R A S$ and $B R A F$ gene mutations in Chinese patients with $\mathrm{mCRC}$, and investigate the prognostic value of distinct codon-specific KRAS mutations and their associations with clinicopathological characteristics.

\section{Materials and methods}

Study population. Based on the database of Sir Run Run Shaw Hospital (Hangzhou, China), a total of 580 patients were searched with histologically confirmed CRC and imaging confirmed metastasis between January 2010 and June 2016, among which 135 patients were tested for mutations in KRAS gene and 128 in $B R A F$ gene. Characteristics of sex, age, body mass index (BMI), location of primary tumor, metastatic sites and the time to metastasis were collected. There were 135 patients, including 85 males and 50 females with the age range, 28-82. Survival analysis was performed in 101 patients between January 2010 and September 2015 who received curative resection for primary tumor. Adjuvant therapy included 5-fluorouracil folinic acid in combination with irinotecan (FOLFIRI) or oxaliplatin (FOLFOX); capecitabine in combination with oxaliplatin (XELOX) or capecitabine alone; with or without targeted drug (cetuximab or bevacizumab). A total of 30 patients received neoadjuvant therapy prior to surgery. All the therapies were based on the corresponding National Comprehensive Cancer Network guideline. The present study was approved by the Institutional Ethics Committee of Sir Run Run Shaw Hospital and informed consent was obtained from each participant.

DNA preparation and quantitative polymerase chain reaction. Tissue samples were fixed in $10 \%$ formalin at ambient temperature for $6 \mathrm{~h}$. DNA was extracted from formalin-fixed paraffin-embedded samples of primary lesions or biopsy specimens. Genomic DNA was extracted with QIAamp ${ }^{\circledR}$ DNA FFPE tissue kit (Qiagen GmbH, Hilden, Germany) according to the manufacturer's instructions. AmoyDx ${ }^{\circledR}$ KRAS Mutation Detection kit and BRAF V600 Mutations Detection kit (both from Amoy Diagnostics Co., Ltd., Xiamen, China) were used to detect $K R A S$ and $B R A F$ status of each DNA sample according to the manufacturer's instructions. The quantitative polymerase chain reaction (qPCR) experiment was performed on Cobas z480 (Roche Molecular Diagnostics, Pleasanton, CA, USA) under the following three stages: one cycle at $95^{\circ} \mathrm{C}$ for $5 \mathrm{~min}, 15$ cycles at $95^{\circ} \mathrm{C}$ for $25 \mathrm{sec}$ and $64^{\circ} \mathrm{C}$ for $20 \mathrm{sec}$ and $72^{\circ} \mathrm{C}$ for $20 \mathrm{sec}, 26$ cycles at $93^{\circ} \mathrm{C}$ for $25 \mathrm{sec}$ and $60^{\circ} \mathrm{C}$ for $35 \mathrm{sec}$ and $72^{\circ} \mathrm{C}$ for $20 \mathrm{sec}$. A result was considered mutation-positive if the $\mathrm{Cq}$ value was $<30$ with a classic $\mathrm{S}$-curve (19). The aforementioned tests were performed in the Molecular Diagnostics Laboratory of Sir Run Run Shaw Hospital.

Statistical analysis. Data was analyzed with $\chi^{2}$ test or Fisher's exact test to compare proportions. The Student's t-test was used
Table I. Frequency of KRAS and BRAF mutations in patients with metastatic colorectal cancer.

\begin{tabular}{ccc}
\hline Amino acid & Case (total) & $(\%)$ \\
\hline KRAS & $45(135)$ & 33.3 \\
G12A & 2 & \\
G12D & 17 & \\
G12V & 12 & \\
G12C & 2 & \\
G12S & 1 & \\
G13D & 11 & 2.3 \\
BRAF & & \\
V600E & $3(128)$ & \\
\hline
\end{tabular}

to compare two groups of continuous data. Data are presented as mean values. The Kaplan-Meier method was performed for survival analysis and log rank test was used to compare the survival distributions. Furthermore, Cox's proportional hazards regression model was chosen to identify the impact of factors on OS. Hazard ratio (HR) was calculated with $95 \%$ confidence interval (CI). $\mathrm{P}<0.05$ was considered to indicate a statistically significant difference. All statistical analysis was performed with SPSS statistical software (version 21.0; IBM Corp., Armonk, NY, USA). Survival curves were plotted in Graph Pad Prism (version 6.0; GraphPad Software, Inc., La Jolla, CA, USA).

\section{Results}

KRAS mutation characteristics. Among the 135 patients with $K R A S$ gene detection data, mutations in exon 2 were identified in $45(33.3 \%)$ patients, of which $34(68.9 \%)$ exhibited a single mutation in codon 12 , and $11(31.1 \%)$ exhibited a single mutation in codon 13 . Codon 12 represented 5 mutational types, while codon 13 represented only 1 (G13D). The most frequently observed mutation was $35 \mathrm{G}>\mathrm{A}$ (G12D), followed by $35 \mathrm{G}>\mathrm{T}$ (G12V), 37.8 and 26.7\%, respectively. The mutational types G12A, G12C and G12S comprised a small part of the mutations in these 2 codons. Of the 135 patients, BRAF codon 600 status was tested in 128 patients. Only 3 patients exhibited a mutation of $\operatorname{V600E}(3 / 128,2.3 \%)$ and none of them possessed KRAS mutations simultaneously. Mutations are summarized in Table I.

Association between KRAS gene mutations and clinicopathological features. The association between clinicopathological features and KRAS codon 12,13, and a 12/13 mutation status are presented in Table II. KRAS gene mutations and KRAS codon 12 mutations were significantly more common in female patients, compared with male patients $(\mathrm{P}<0.05)$. Compared with left-sided colon, right-sided colon experienced a significantly increased number of KRAS codon 13 mutations $(\mathrm{P}<0.05)$. No other significant associations were identified.

Prognostic value of KRAS codon 12 mutation. Among the 135 patients, 101 patients that received curative or palliative resection for CRC were included for survival analysis. In a 
Table II. Clinicopathological features according to KRAS codon status in 135 patients with metastatic colorectal cancer.

\begin{tabular}{|c|c|c|c|c|c|c|c|c|c|c|}
\hline \multirow[b]{2}{*}{ Parameter } & \multirow[b]{2}{*}{ No. } & \multicolumn{3}{|c|}{ KRAS codon 12} & \multicolumn{3}{|c|}{ KRAS codon 13} & \multicolumn{3}{|c|}{ KRAS codon 12 and 13} \\
\hline & & $\mathrm{Wt}$ & $\begin{array}{l}\text { Mutation } \\
(\mathrm{n}, \%)\end{array}$ & P-value & $\mathrm{Wt}$ & $\begin{array}{c}\text { Mutation } \\
(\mathrm{n}, \%)\end{array}$ & P-value & $\mathrm{Wt}$ & $\begin{array}{l}\text { Mutation } \\
(\mathrm{n}, \%)\end{array}$ & P-value \\
\hline Sex & & & & $0.03^{\mathrm{a}, \mathrm{b}}$ & & & $>0.09^{c}$ & & & $0.04^{\mathrm{a}, \mathrm{b}}$ \\
\hline Male & 85 & 69 & $16(18.8)$ & & 78 & $7(8.2)$ & & 62 & $23(27.1)$ & \\
\hline Female & 50 & 32 & $18(36.0)$ & & 46 & $4(8.0)$ & & 28 & $22(44.0)$ & \\
\hline Age (years) ${ }^{\mathrm{d}}$ & 58.2 & 57.7 & 59.8 & $0.34^{\mathrm{e}}$ & 58.7 & 53.3 & $0.79^{\mathrm{e}}$ & 58.3 & 58.1 & $0.65^{\mathrm{e}}$ \\
\hline $\begin{array}{l}\text { Body-mass } \\
\text { index }^{d}\end{array}$ & 22.9 & 23.1 & 22.5 & $0.30^{\mathrm{e}}$ & 23.0 & 22.3 & $0.82^{\mathrm{e}}$ & 23.2 & 22.4 & $0.26^{\mathrm{e}}$ \\
\hline Location & & & & $0.44^{\mathrm{b}}$ & & & $0.04^{\mathrm{c}}$ & & & $0.51^{\mathrm{b}}$ \\
\hline Right-sided & 43 & 34 & $9(20.9)$ & & 36 & $7(16.3)$ & & 27 & $16(37.2)$ & \\
\hline Left-sided & 92 & 67 & $25(27.2)$ & & 88 & $4(4.3)$ & & 63 & $29(31.5)$ & \\
\hline Metastasis & & & & $0.81^{\mathrm{b}}$ & & & $0.74^{\mathrm{b}}$ & & & $1.00^{\mathrm{b}}$ \\
\hline Hepatic & 42 & 32 & $10(23.8)$ & & 38 & $4(9.5)$ & & 28 & $14(33.3)$ & \\
\hline Extrahepatic & 93 & 69 & $24(25.8)$ & & 86 & $7(7.5)$ & & 62 & $31(33.3)$ & \\
\hline $\begin{array}{l}\text { Synchronous } \\
\text { metastasis }\end{array}$ & & & & $0.71^{b}$ & & & $0.12^{b}$ & & & $0.58^{\mathrm{b}}$ \\
\hline Yes & 100 & 74 & $26(26.0)$ & & 94 & $6(6.0)$ & & 68 & $32(32.0)$ & \\
\hline No & 35 & 27 & 8 (22.9) & & 30 & $5(14.3)$ & & 22 & $13(37.1)$ & \\
\hline
\end{tabular}

${ }^{\mathrm{a}} \mathrm{P}<0.05 ;{ }^{\mathrm{b}} \chi^{2}$ test; ${ }^{\mathrm{c}}$ Fisher's exact test; ${ }^{\mathrm{d}}$ data presented as the mean; ${ }^{\mathrm{e}}$ Student's t-test. Wt, wild-type.
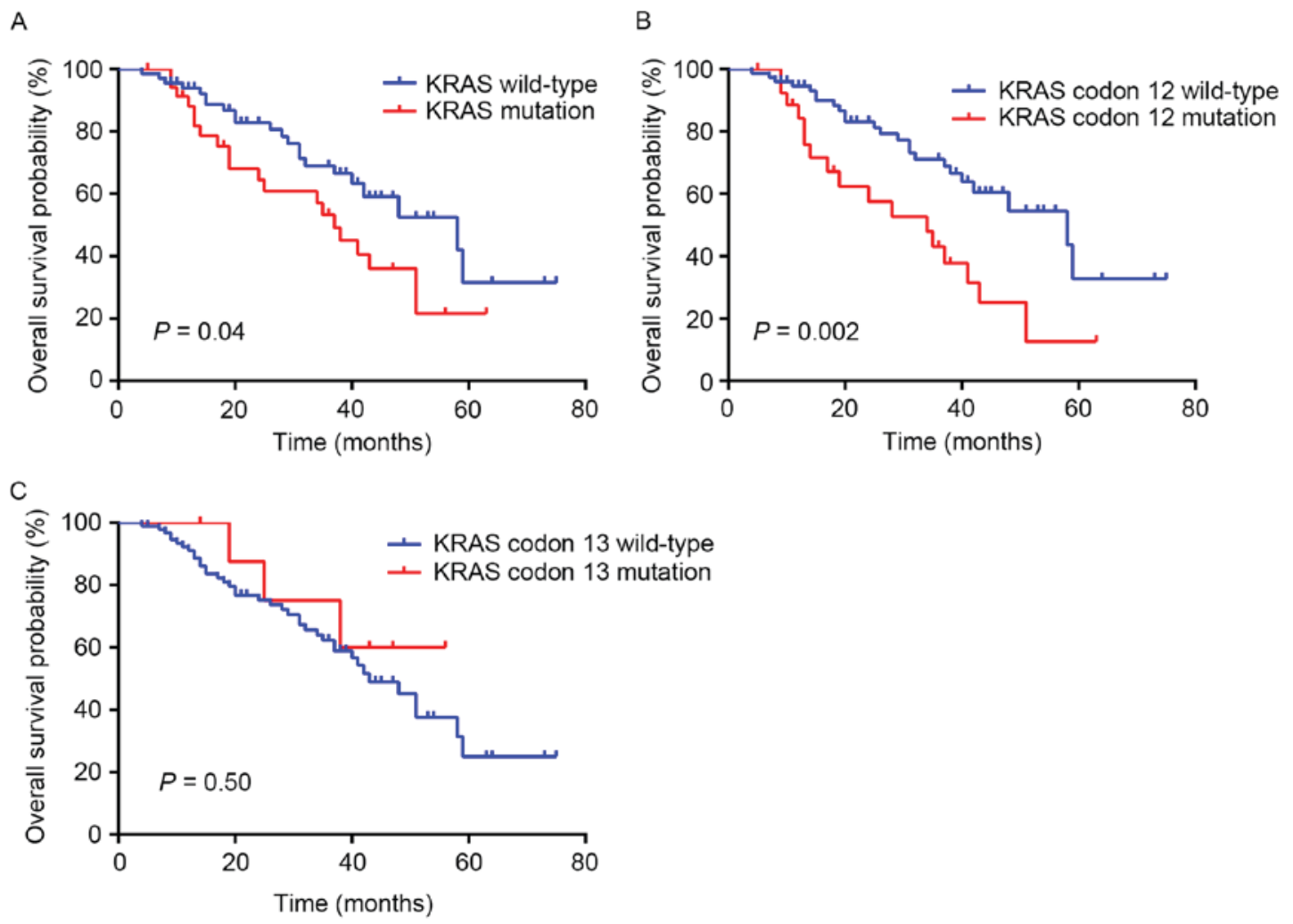

Figure 1. Kaplan-Meier curves of overall survival according to (A) KRAS mutation status, (B) KRAS codon 12 mutation status and (C) KRAS codon 13 mutation status in 101 patients.

Kaplan-Meier survival analysis of the KRAS gene status in the 101 patients, KRAS mutations were highly associated with a poorer survival (log-rank $\mathrm{P}=0.04$; median survival, 37 months in the KRAS mutant vs. 58 months in the KRAS wild-type; 
Table III. Univariate analysis of overall survival for 101 patients.

\begin{tabular}{|c|c|c|}
\hline Variable & $\begin{array}{c}\text { Hazard ratio } \\
(95 \% \text { confidence interval) }\end{array}$ & $\mathrm{P}$-value \\
\hline Sex & & 0.17 \\
\hline Male & Ref. & \\
\hline Female & $1.547(0.832-2.875)$ & \\
\hline Age (years) & $1.012(0.985-1.039)$ & 0.39 \\
\hline Location & & 0.41 \\
\hline Right-sided & Ref. & \\
\hline Left-sided & $0.758(0.393-1.462)$ & \\
\hline Metastasis & & 0.64 \\
\hline Hepatic & Ref. & \\
\hline Extrahepatic & $1.194(0.569-2.507)$ & \\
\hline $\begin{array}{l}\text { Synchronous } \\
\text { metastasis }\end{array}$ & & 0.16 \\
\hline Yes & Ref. & \\
\hline No & $0.633(0.336-1.195)$ & \\
\hline Targeted drug & & 0.85 \\
\hline No & Ref. & \\
\hline Yes & $0.937(0.479-1.834)$ & \\
\hline Neoadjuvant therapy & & 0.78 \\
\hline No & Ref. & \\
\hline Yes & $1.101(0.569-2.129)$ & \\
\hline KRAS status & & $0.04^{\mathrm{a}}$ \\
\hline Wt & Ref. & \\
\hline Mutant & $1.884(1.026-3.462)$ & \\
\hline Codon 12 status & & $<0.01$ \\
\hline $\mathrm{Wt}$ & Ref. & \\
\hline Mutant & $2.528(1.369-4.668)$ & \\
\hline Codon 13 status & & 0.49 \\
\hline $\mathrm{Wt}$ & Ref. & \\
\hline Mutant & $0.657(0.202-2.135)$ & \\
\hline
\end{tabular}

${ }^{a} \mathrm{P}<0.05$. Ref., reference; wt, wild-type.

Fig. 1A). In particular, patients with $K R A S$ codon 12 wild-type experienced a median survival of 58 months, which was significantly increased, compared with patients with KRAS codon 12 mutation whose median survival was 34 months (log-rank $\mathrm{P}=0.002$; Fig. 1B). The survival analysis indicated no difference between patients with and without KRAS codon 13 mutation $(\mathrm{P}=0.50$; Fig. $1 \mathrm{C})$.

Analysis of prognostic risk factors. Age, sex, the location of primary tumor and metastasis, the time of metastasis, the use of target drug and neoadjuvant therapy, and the KRAS gene status were analyzed with the Cox regression model (Table III). With the exception of KRAS codon 12 status, none of these factors exhibited a predictive value for poor prognosis. The patients with KRAS codon 12 mutations presented a significant decrease in overall survival $(\mathrm{HR}=2.528,95 \%$ $\mathrm{CI}=1.369-4.668, \mathrm{P}=0.003)$. In comparison, KRAS codon
13 mutants demonstrated no significant effect on survival $(\mathrm{HR}=0.657,95 \% \mathrm{CI}=0.202-2.135, \mathrm{P}=0.49)$. Management of targeted and neoadjuvant therapy was not associated with risk of mortality $(\mathrm{P}=0.85 ; \mathrm{P}=0.78$, respectively). Further analysis revealed that rather than c.35G $>\mathrm{C}(\mathrm{G} 12 \mathrm{~A})$ or c.35G $>\mathrm{T}(\mathrm{G} 12 \mathrm{C})$, c. $35 \mathrm{G}>\mathrm{A}(\mathrm{G} 12 \mathrm{D})$ and c. $35 \mathrm{G}>\mathrm{T}(\mathrm{G} 12 \mathrm{~V})$ were associated with a significantly decreased OS compared with KRAS wild-type $(\mathrm{HR}=2.313,95 \% \mathrm{CI}=1.069-5.004, \mathrm{P}=0.03 ; \mathrm{HR}=2.621,95 \%$ $\mathrm{CI}=1.057-6.497, \mathrm{P}=0.04$, respectively; Table IV).

\section{Discussion}

In the present study, the frequencies of $K R A S$ and $B R A F$ gene mutations were determined in Chinese patients with $\mathrm{mCRC}$. The association between KRAS mutations with clinicopathological features was investigated. KRAS codon 12 mutations, especially G12D and G12V were revealed to exhibit predictive value for poor overall survival. To the best of our knowledge, studies concerning KRAS mutations have primarily been conducted only in the Western population $(10,11)$. The impact of $K R A S$ mutation, especially its different mutational sites, on the survival of Chinese population was uncertain and controversial.

The frequency of KRAS mutations (33.3\%) and $B R A F$ mutations $(2.3 \%)$ in the present study were in accordance with a previous retrospective observational study that also involved Chinese patients with mCRC (34.8 and 3.4\%, respectively) (20). However, the KRAS and BRAF mutation rate was slightly higher in the Western population (37.3 and 6\%) (10). Since the morbidity and mortality of CRC in China were different from that in Western countries, the KRAS and BRAF mutation rates in different regions required further exploration (21).

The majority of KRAS mutations have been revealed to occur in codon 12 and 13 (3). The detection of associations between KRAS mutations and clinicopathological features had been performed widely; however, the data was lacking when codon 12 and 13 were considered separately $(14,22,23)$. In the present study, compared with male patients, KRAS codon 12 mutations were more common in female patients compared with codon 13 mutations. Notably, while $K R A S$ mutations (including codon 12 and 13) were not associated with the location of primary tumor, codon 13 mutation (G13D) itself was likely to occur in the tumors arising from right-sided colon. Recently, it was accepted that patients with right-sided colon cancer experienced an inferior OS rate (24). Additionally, increasing evidence suggests that mutations in KRAS codon 13 predict a poor outcome $(12,18)$. In the present study, G13D mutation was associated with right-sided colon cancer; however, exhibited no prognostic significance, which may be explained by the small sample size. As for patterns of recurrence, Margonis et al (18) suggested that patients with KRAS codon 13 mutations, rather than codon 12 mutations possessed an increased risk of extrahepatic recurrence and lung-specific recurrence. Nevertheless, the results of the present study identified no difference in the patterns of tumor progression (including metastatic sites and time to recurrence) according to codon 12 or 13 mutation status.

The distribution of mutations in codon 12 and 13 varied in distinct studies. G12D in the present study was the most prominent subtype which was congruent with data from Caucasian and other Chinese mCRC (25-27). It had been reported that 
Table IV. Analysis of overall survival according to KRAS codon 12 mutations by Cox regression analysis.

\begin{tabular}{lcccc}
\hline Nucleotide & Amino acid & Total number & $\begin{array}{c}\text { Hazard ratio } \\
\text { (95\% confidence interval) }\end{array}$ \\
\hline Wild-type & & 74 & Ref. \\
c.35G $>$ A & G12D & 13 & $2.313(1.069-5.004)$ & $0.03^{\mathrm{a}}$ \\
c.35G $>\mathrm{T}$ & $\mathrm{G} 12 \mathrm{~V}$ & 10 & $2.621(1.057-6.497)$ & $0.04^{\mathrm{a}}$ \\
c.35G $>\mathrm{C}$ & $\mathrm{G} 12 \mathrm{~A}$ & 2 & $3.308(0.432-25.358)$ & 0.25 \\
c.34G $>\mathrm{T}$ & $\mathrm{G} 12 \mathrm{C}$ & 2 & $3.991(0.928-17.165)$ & $0.06^{\mathrm{a}}$ \\
\hline
\end{tabular}

${ }^{\mathrm{a}} \mathrm{P}<0.05$.

different subtypes of KRAS mutations may confer variable tumor biology $(28,29)$. A previous study involving surgically resected lung adenocarcinoma revealed that $\mathrm{G} 12 \mathrm{C}$ mutation was associated with poorer outcome compared with other subtypes of mutations (28). Another study in Chinese patients with CRC demonstrated that KRAS codon 13 mutations, in particular G13D, were associated with significantly decreased OS rates (12). However, in the present study, KRAS codon 13 mutations had no effect on OS, but mutations in KRAS codon 12 were predictive for poor prognosis. This result was consistent with the evidence from in vitro studies, in which codon 12 mutations may increase aggressiveness due to increased transforming capacity and decreased levels of apoptosis $(16,30)$. Previously, meta-analysis also revealed the predictive value that codon 12 mutations possessed by pooling the data from five randomized trials researching patients with $\mathrm{mCRC}$ in Western countries (10). In that meta-analysis, G12C was associated with inferior OS compared with $K R A S$ wild-type; however, the results of the present study demonstrated that G12D and G12V were associated with decreased OS times. The prognostic value of codon and amino acid specific KRAS mutations has been discussed on several cancer types. For example, Bournet et al (31) reported that KRAS G12D mutant was an independent prognostic factor for unresectable pancreatic cancer. It had been proposed that in non-small cell lung cancer, the G12D mutation subtype was associated with the activation of the phosphoinositide 3-kinase/AKT serine/threonine kinase (AKT) and MEK signaling whereas mutation G12V or G12C preferred to activate Raf and Ral, and decreased growth factor-dependent AKT activation $(32,33)$. These findings led to the present study in which the association between signaling pathways and the role of $K R A S$ mutation subtypes on prognosis of patients with CRC were investigated, particularly in patients with $\mathrm{mCRC}$ from different regions.

$B R A F$ V600E mutation has also been widely identified in CRC (34). It is considered to be associated with poor clinical outcome and may have confounding effect with KRAS mutations $(35,36) . B R A F$ V600E mutation was not included in the further analysis due to its extremely low mutation rate $(2.3 \%)$.

There were several limitations to the present study, for example it was a retrospective study with a small sample size. Microsatellite instability and other family members of $R A S$ gene that serve a function in CRC were not included. The therapeutic regimens varied between the patients, which may have resulted in the heterogeneity. However, no significant difference was observed in the number of patients receiving neoadjuvant therapy and targeted therapy between the groups of codon 12 mutation, and codon 12 wild-type $(\mathrm{P}>0.05$; data not shown). Additionally, the Cox regression model identified that whether receiving these two therapies or not was not a factor affecting the survival.

In conclusion, the results of the present study indicate that codon 12 mutations may predict poor OS in Chinese patients with $\mathrm{mCRC}$, and further investigation demonstrated that G12D and G12V served as an indicator of poor prognosis in this specific population. In future clinical studies of CRC, the significance of gene mutation subtypes should be brought into consideration.

\section{Acknowledgements}

The present study was supported by the National Natural Science Foundation of China (grant no. 81272681). The AmoyDx ${ }^{\circledR}$ KRAS Mutation Detection kit, BRAF V600 Mutations Detection kit and corresponding primers are patented (patent no. ZL 200910111501.6 ).

\section{References}

1. Cunningham D, Atkin W, Lenz HJ, Lynch HT, Minsky B, Nordlinger B and Starling N: Colorectal cancer. Lancet 375: 1030-1047, 2010.

2. Ng SC and Wong SH: Colorectal cancer screening in Asia. Br Med Bull 105: 29-42, 2013.

3. Sung JJ, Lau JY, Young GP, Sano Y, Chiu HM, Byeon JS, Yeoh KG, Goh KL, Sollano J, Rerknimitr R, et al: Asia Pacific consensus recommendations for colorectal cancer screening. Gut 57: 1166-1176, 2008.

4. Shao YC, Chang YY, Lin JK, Lin CC, Wang HS, Yang SH, Jiang JK, Lan YT, Lin TC, Li AF, et al: Neoadjuvant chemotherapy can improve outcome of colorectal cancer patients with unresectable metastasis. Int J Colorectal Dis 28: 1359-1365, 2013.

5. Ohhara Y, Fukuda N, Takeuchi S, Honma R, Shimizu Y, Kinoshita I and Dosaka-Akita H: Role of targeted therapy in metastatic colorectal cancer. World J Gastrointest Oncol 8: 642-655, 2016.

6. Graham DM, Coyle VM, Kennedy RD and Wilson RH: Molecular subtypes and personalized therapy in metastatic colorectal cancer. Curr Colorectal Cancer Rep 12: 141-150, 2016.

7. De Roock W, De Vriendt V, Normanno N, Ciardiello F and Tejpar S: KRAS, BRAF, PIK3CA, and PTEN mutations: Implications for targeted therapies in metastatic colorectal cancer. Lancet Oncol 12: 594-603, 2011.

8. McCubrey JA, Steelman LS, Abrams SL, Lee JT, Chang F, Bertrand FE, Navolanic PM, Terrian DM, Franklin RA, D'Assoro AB, et al: Roles of the RAF/MEK/ERK and PI3K/PTEN/AKT pathways in malignant transformation and drug resistance. Adv Enzyme Regul 46: 249-279, 2006. 
9. Van Cutsem E, Köhne CH, Láng I, Folprecht G, Nowacki MP, Cascinu S, Shchepotin I, Maurel J, Cunningham D, Tejpar S, et al: Cetuximab plus irinotecan, fluorouracil, and leucovorin as first-line treatment for metastatic colorectal cancer: Updated analysis of overall survival according to tumor KRAS and BRAF mutation status. J Clin Oncol 29: 2011-2019, 2011.

10. Modest DP, Ricard I, Heinemann V, Hegewisch-Becker S, Schmiegel W, Porschen R, Stintzing S, Graeven U, Arnold D, von Weikersthal LF, et al: Outcome according to KRAS-, NRAS- and BRAF-mutation as well as KRAS mutation variants: Pooled analysis of five randomized trials in metastatic colorectal cancer by the AIO colorectal cancer study group. Ann Oncol 27: 1746-1753, 2016.

11. Andreatos N, Ronnekleiv-Kelly S, Margonis GA, Sasaki K, Gani F, Amini N, Wilson A and Pawlik TM: From bench to bedside: Clinical implications of KRAS status in patients with colorectal liver metastasis. Surg Oncol 25: 332-338, 2016.

12. Chen J, Guo F, Shi X, Zhang L, Zhang A, Jin H and He Y: BRAF V600E mutation and KRAS codon 13 mutations predict poor survival in Chinese colorectal cancer patients. BMC Cancer 14: $802,2014$.

13. Neumann J, Zeindl-Eberhart E, Kirchner T and Jung A: Frequency and type of KRAS mutations in routine diagnostic analysis of metastatic colorectal cancer. Pathol Res Pract 205 858-862, 2009

14. Li Z, Chen Y, Wang D, Wang G, He L and Suo J: Detection of KRAS mutations and their associations with clinicopathological features and survival in Chinese colorectal cancer patients. J Int Med Res 40: 1589-1598, 2012.

15. De Roock W, Jonker DJ, Di Nicolantonio F, Sartore-Bianchi A Tu D, Siena S, Lamba S, Arena S, Frattini M, Piessevaux H, et al: Association of KRAS p.G13D mutation with outcome in patients with chemotherapy-refractory metastatic colorectal cancer treated with cetuximab. JAMA 304: 1812-1820, 2010.

16. Guerrero S, Casanova I, Farré L, Mazo A, Capellà G and Mangues R: K-ras codon 12 mutation induces higher level of resistance to apoptosis and predisposition to anchorage-independent growth than codon 13 mutation or proto-oncogene overexpression. Cancer Res 60: 6750-6756, 2000.

17. Samowitz WS, Curtin K, Schaffer D, Robertson M, Leppert M and Slattery ML: Relationship of Ki-ras mutations in colon cancers to tumor location, stage, and survival: A population-based study. Cancer Epidemiol Biomarkers Prev 9: 1193-1197, 2000.

18. Margonis GA, Kim Y, Sasaki K, Samaha M, Amini N and Pawlik TM: Codon 13 KRAS mutation predicts patterns of recurrence in patients undergoing hepatectomy for colorectal liver metastases. Cancer 122: 2698-2707, 2016.

19. Zhang H, Zheng X, Ji T, Fu L, Bai D, Liao Y, Zhang H, Ding Y and Zheng L: Comparative screening of K-ras mutations in colorectal cancer and lung cancer patients using a novel real-time PCR with ADx-K-ras Kit and Sanger DNA sequencing. Cell Biochem Biophys 62: 415-420, 2012.

20. LiZZ, Wang F, Zhang ZC, Wang F, Zhao Q, Zhang DS, Wang FH, Wang ZQ, Luo HY, He MM, et al: Mutation profiling in chinese patients with metastatic colorectal cancer and its correlation with clinicopathological features and anti-EGFR treatment response. Oncotarget 7: 28356-28368, 2016.

21. Favoriti P, Carbone G, Greco M, Pirozzi F, Pirozzi RE and Corcione F: Worldwide burden of colorectal cancer: A review. Updates Surg 68: 7-11, 2016.

22. Price TJ, Bruhn MA, Lee CK, Hardingham JE, Townsend AR, Mann KP, Simes J, Weickhardt A, Wrin JW, Wilson K, et al: Correlation of extended RAS and PIK3CA gene mutation status with outcomes from the phase III AGITG MAX STUDY involving capecitabine alone or in combination with bevacizumab plus or minus mitomycin $\mathrm{C}$ in advanced colorectal cancer. Br J Cancer 112: 963-970, 2015.
23. Karapetis CS, Khambata-Ford S, Jonker DJ, O'Callaghan CJ, Tu D, Tebbutt NC, Simes RJ, Chalchal H, Shapiro JD, Robitaille S, et al: K-ras mutations and benefit from cetuximab in advanced colorectal cancer. N Engl J Med 359: 1757-1765, 2008.

24. Tejpar S, Stintzing S, Ciardiello F, Tabernero J, Van Cutsem E, Beier F, Esser R, Lenz HJ and Heinemann V: Prognostic and predictive relevance of primary tumor location in patients with RAS wild-type metastatic colorectal cancer: Retrospective analyses of the CRYSTAL and FIRE-3 trials. JAMA Oncol: Oct 10, 2016 (Epub ahead of print).

25. Li FH, Shen L, Li ZH, Luo HY, Qiu MZ, Zhang HZ, Li YH and Xu RH: Impact of KRAS mutation and PTEN expression on cetuximab-treated colorectal cancer. World J Gastroenterol 16: 5881-5888, 2010

26. Mao C, Zhou J, Yang Z, Huang Y, Wu X, Shen H, Tang J and Chen Q: KRAS, BRAF and PIK3CA mutations and the loss of PTEN expression in Chinese patients with colorectal cancer. PLoS One 7: e36653, 2012.

27. Frattini M, Saletti P, Romagnani E, Martin V, Molinari F, Ghisletta M, Camponovo A, Etienne LL, Cavalli F and Mazzucchelli L: PTEN loss of expression predicts cetuximab efficacy in metastatic colorectal cancer patients. Br J Cancer 97: $1139-1145,2007$

28. Nadal E, Chen G, Prensner JR, Shiratsuchi H, Sam C, Zhao L, Kalemkerian GP, Brenner D, Lin J, Reddy RM, et al: KRAS-G12C mutation is associated with poor outcome in surgically resected lung adenocarcinoma. J Thorac Oncol 9: 1513-1522, 2014.

29. Tejpar S, Celik I, Schlichting M, Sartorius U, Bokemeyer C and Van Cutsem E: Association of KRAS G13D tumor mutations with outcome in patients with metastatic colorectal cancer treated with first-line chemotherapy with or without cetuximab. J Clin Oncol 30: 3570-3577, 2012.

30. Ward RL, Todd AV, Santiago F, O'Connor T and Hawkins NJ: Activation of the K-ras oncogene in colorectal neoplasms is associated with decreased apoptosis. Cancer 79: 1106-1113, 1997.

31. Bournet B, Muscari F, Buscail C, Assenat E, Barthet M,Hammel P, Selves J, Guimbaud R, Cordelier P and Buscail L: KRAS G12D mutation subtype is a prognostic factor for advanced pancreatic adenocarcinoma. Clin Transl Gastroenterol 7: e157, 2016.

32. Ihle NT, Byers LA, Kim ES,Saintigny P,Lee JJ,Blumenschein GR, Tsao A, Liu S, Larsen JE, Wang J, et al: Effect of KRAS oncogene substitutions on protein behavior: Implications for signaling and clinical outcome. J Natl Cancer Inst 104: 228-239, 2012.

33. Guibert N, Ilie M, Long E, Hofman V, Bouhlel L, Brest P, Mograbi B, Marquette CH, Didier A, Mazieres J and Hofman P: KRAS mutations in lung adenocarcinoma: Molecular and epidemiological characteristics, methods for detection, and therapeutic strategy perspectives. Curr Mol Med 15: 418-432, 2015.

34. Li WQ, Kawakami K, Ruszkiewicz A, Bennett G, Moore J and Iacopetta B: BRAF mutations are associated with distinctive clinical, pathological and molecular features of colorectal cancer independently of microsatellite instability status. Mol Cancer 5: 2, 2006

35. Yokota T, Ura T, Shibata N, Takahari D, Shitara K, Nomura M, Kondo C, Mizota A, Utsunomiya S, Muro K and Yatabe Y: BRAF mutation is a powerful prognostic factor in advanced and recurrent colorectal cancer. Br J Cancer 104: 856-862, 2011.

36. Imamura Y, Morikawa T, Liao X, Lochhead P, Kuchiba A, Yamauchi M, Qian ZR, Nishihara R, Meyerhardt JA, Haigis KM, et al: Specific mutations in KRAS codons 12 and 13, and patient prognosis in 1075 BRAF wild-type colorectal cancers. Clin Cancer Res 18: 4753-4763, 2012. 